\title{
Professional monitoring - A basis for citizen science projects with sustainable impact?
}

\author{
Janette Siebert ${ }^{*}$ * \\ Austrian Ornithological Centre, Konrad Lorenz Institute of Ethology, University of Veterinary Medicine, \\ Vienna, Austria \\ E-mail: janette.siebert@vetmeduni.ac.at

\section{Natalie Eder} \\ Austrian Ornithological Centre, Konrad Lorenz Institute of Ethology, University of Veterinary Medicine, \\ Vienna, Austria \\ E-mail: natalie.eder@vetmeduni.ac.at
}

\section{Elena Kmetova-Biro}

Austrian Ornithological Centre, Konrad Lorenz Institute of Ethology, University of Veterinary Medicine, Vienna, Austria

E-mail: elena.kemtova-biro@vetmeduni.ac.at

\section{Richard Zink}

Austrian Ornithological Centre, Konrad Lorenz Institute of Ethology, University of Veterinary Medicine,

Vienna, Austria

E-mail: richard.zink@vetmeduni.ac.at

Hundreds of swallow nests were discovered with help of citizen scientists in Lower Austria in 2019. With further support of trainees from the AOC Seebarn, a possible basis for long-term monitoring of swallow nests in Lower Austria was created, providing first insights into public acceptance of house martins and barn swallows. The current results are to be seen as a snapshot of the year 2019. Continuation and expansion of the swallow nest monitoring based on citizen science aims to evaluate the sustainable impact of citizen science for a long-term conservation project.

Vienna - Austria 


\section{Introduction}

House martins (Delichon urbicum) and barn swallows (Hirundo rustica) belong to the four swallow species native to Austria, that live in our immediate vicinity [1]. The original rock and niche breeders in shore caves and semi-caves have become typical synanthropes that build their nests on facades and walls of buildings, barns and stables. Abandonment as well as modernization of agricultural livestock farming, urbanization of many villages, and increasing food shortages are some reasons for population declines [2]. In Austria, the population development of barn swallows has been stable over the last years. For house martins, however, declining population trends have been observed [3]. In 2019, the Austrian Ornithological Centre - Seebarn Branch (AOC Seebarn) launched a citizen science project to report house martin and barn swallow nests in Lower Austria.

The aim of the study, besides finding nesting sites of both swallow species, was divided into two main points:

1) Setting up a basis for long term monitoring by citizen scientists and a comparison of the rate of feedback sent through paper data forms or via the project page.

2) Determination of overall awareness and acceptance of the local community towards the two swallow species, using a questionnaire-based field study, conducted by trainees of the AOC Seebarn.

\section{Methods}

In March 2019, the AOC Seebarn launched the project site wildenachbarn.at, focusing on wildlife observations in rural areas. The same platform was used as an interface between citizen scientists and experts to exchange data regarding swallow nest observations during the period of the project. It was important to have a user-friendly tool to increase the citizen participation rate.

The reporting of swallow nest observations for citizen scientists was possible via project page and paper data forms. Nests reported via project pages could, in order to increase the usability, also be done without registration. The input mask was specified for nest reports. Mandatory fields to fill out were species name, date/time of sighting, reason for the report, type of report and number of nests. Additionally, information on nest occupation could be given. Furthermore, up to three images could be uploaded for each observation. This was only possible for registered observers of the online platform.

On paper data forms information could be given about species name, date, number of nests and nest occupation status. Furthermore, the paper data form offered preset data fields for particular details (nest location, number of fledglings, etc.). By contrast, the online form only contained an optional field for free input of additional information. All observations were verified by scientists of the AOC Seebarn and re-identified if necessary. 
Professional monitoring - A basis for citizen science projects with sustainable impact?

Janette Siebert, Natalie Eder, Elena Kmetova-Biro, Richard Zink

At the same time trainees of the AOC Seebarn conducted a comprehensive questionnaire based mapping of the nesting sites of both swallow species, including an information campaign in the villages of Seebarn (district of Tulln) and Schiltern (district of Krems Land) visiting each three times at intervals of four weeks in the period April to June 2019.

\section{Science communication of the project}

Additional information about the aim of the study as well as species fact sheets were provided through the project page and the paper data form, sent by regular mail. Residents of the district of Tulln were invited to report the presence of swallow nests from April to September 2019 , using the project page wildenachbarn.at or a paper data form. Invitations were extended to people through events, an online newsletter, social media, the project page and related websites, newspapers (district and communal level), and by regular mail.

\section{Results}

A total of 115 filled questionnaires were received by mail and online in 2019, reporting a total population of 650 nests of the two studied swallow species (Fig 1). The majority of all nest reports $(69 \%)$ were received online via project homepage, followed by paper data forms $(31 \%)$.

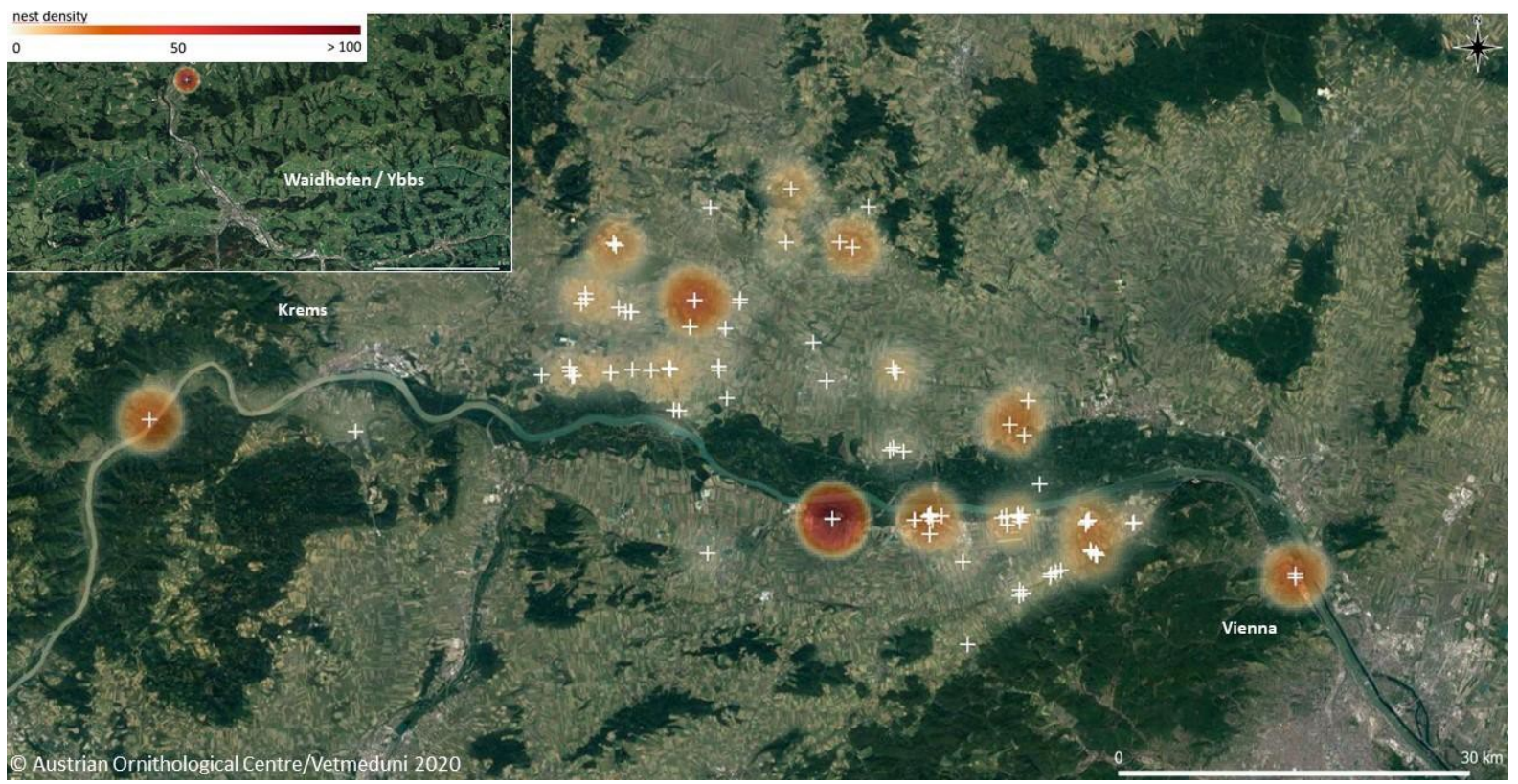

Fig 1: Heatmap of nests reported by citizen scientists. (Number of respondents $=115,+=$ nest reports)

The majority of the citizen scientists (84\%) reported nest locations only once. Almost half of all participants (48\%) did not give any further information (Fig 2: A and B). The given additional information was provided primarily by those respondents who used the paper data forms ( $89 \%$ of all data forms). Of those reporting through the project website $32 \%$ provided additional information about the nests. 


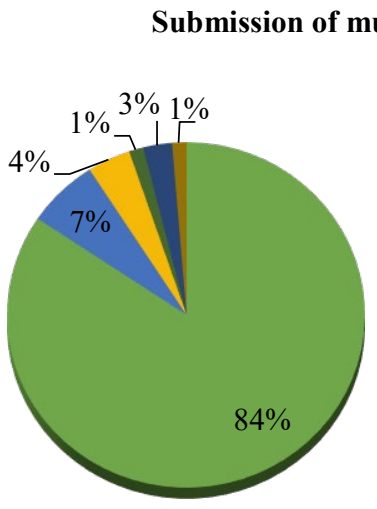

$$
\begin{aligned}
& \varpi \text { single report } \\
& - \text { two-time report } \\
& \square \text { three-time report } \\
& - \text { four-time report } \\
& - \text { five-time report } \\
& ->\text { five-time reports }
\end{aligned}
$$$$
\text { reports }
$$

A
How often was additional information provided?

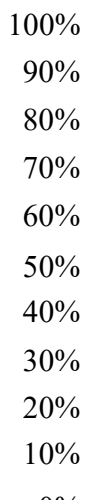

$0 \%$

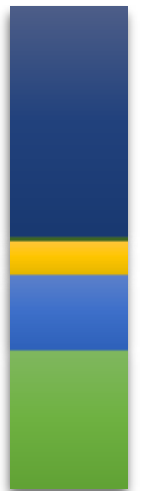

no additional data entries

- 4 additional data entries

3 additional data entries

- 2 additional data entries

1 additional data entry

Fig 2: Number of reports (A) and number of additional data entries (B) by citizen scientists. Number of respondents = 115 .

A survey done by trainees of the AOC Seebarn showed that $71 \%$ (Seebarn) and $44 \%$ (Schiltern) of the local people could not reliably distinguish between the two swallow species. The respondents in both locations showed a predominantly positive attitude and acceptance towards new nests and nesting aids (Fig 3).

Acceptance of new nests and nesting aids

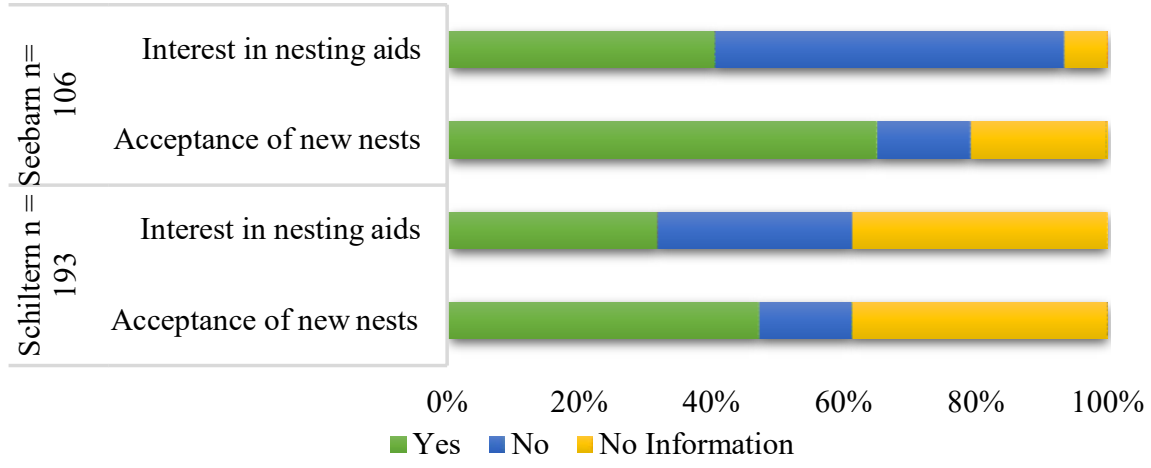

Fig 3: Acceptance survey of the citizens in the villages Seebarn and Schiltern by trainees of the AOC Seebarn.

\section{Conclusions and Implications}

The history of citizen science in bird monitoring goes far back in time [4]. Despite the pleasingly high number of nests found in 2019, the low rate of multiple nest reports in our study suggests that the importance of multiple observations of nest locations to determine population sizes, may not have been communicated clearly enough. In future seasons the impact of this season's student-guided monitoring work on the continued motivation of citizen scientists to report nests independently, and thus on the sustainability of a long-term monitoring effort, should become clearer.

Citizen science-based bird monitoring projects can determine patterns of distribution and abundance on a large scale [5]. In many instances, citizens reported the discovery of single nests or small nest colonies, only a few of the nest-reports related to the discovery of locations with large colonies. Specific response options resulted in nest-reports with a higher information 
Professional monitoring - A basis for citizen science projects with sustainable impact?

Janette Siebert, Natalie Eder, Elena Kmetova-Biro, Richard Zink

content. Since the project page did provide specific enough input fields, this tool should be adapted to provide opportunities for entering additional data, especially since swallow nests were preferentially reported online. Knowledge deficits among the citizen scientists in the differentiation of the two swallow species leads to doubts about the quality of nest reports. The willingness to accept new swallow nests as well as artificial nesting aids is possibly reflected in the participation of citizen scientists in the project and requires further investigations.

\section{Acknowledgements}

Our special thanks are extended to the inhabitants of Seebarn and Schiltern for their willingness to support the trainees' research and our study. Moreover, we would also like to thank all the participating citizen scientists for making this study possible. Also special thanks to both Samira Linhart and Peter Kittenberger for their engagement and great internship work.

\section{References}

[1] Donnerbaum, K. \& Wichmann, G., Die Verbreitung der Mehlschwalbe in Wien - Bericht 2000. Natur und Naturschutz - Studien der Wiener Umweltschutzabteilung (MA 22) 38: 1 - 25 (2000).

[2] Glutz von Blotzheim, U. N., Alaudidae - Hirundinidae/Lerchen und Schwalben in Handbuchder Vögel Mitteleuropas Band 10 / I - Passeriformes (1. Teil). AULA-Verlag GmbH(1985).

[3] Teufelbauer, N., B. S. Seaman \& M. Dvorak, Population changes of common Austrian breeding birds in the period 1998-2016 - Results of the breeding bird monitoring scheme. Egretta 55: 43-76 (2017).

[4] Butcher, G. S., Fuller, M. R., McAllister, L. S. \& Geissler, P. H., An Evaluation of the Christmas Bird Count for Monitoring Population Trends of Selected Species. Wildl. Soc. 18: 129-134(1990).

[5] McCaffrey, R., Using Citizen Science in Urban Bird Studies. Urban Habitats 3: 70-86 (2005). 